\title{
Clinical significance of anatomical urethral length on stress urinary incontinence women
}

This article was published in the following Dove Press journal:

International Journal of Women's Health

\section{Yu Seob Shin \\ Jae Hyung You \\ ji Won On \\ Myung Ki Kim}

Department of Urology, Chonbuk National University Medical School, Research Institute of National University - Biomedical Research Institute of Chonbuk National University Hospital, Jeonju, Republic of Korea Clinical Medicine of Chonbuk
Correspondence: Myung Ki Kim Department of Urology, Medical 634-I8, Geumam-dong, Deokjin-gu, Jeonju 56I-7I2, Republic of Korea Tel +82 632502574

Fax $+8263250 \quad 1564$

Email mkkim@jbnu.ac.kr School, Chonbuk National University,

Objective: To evaluate the association between the length of the female urethra and urodynamic study (UDS) parameters in patients presenting with stress urinary incontinence (SUI).

Patients and methods: We retrospectively enrolled 391 women who underwent a transobturator adjustable tape sling implantation for the management of SUI between April 2009 and March 2016. All patients underwent a physical examination and UDS. Filling cystometry data that were evaluated included the Valsalva leak point pressure, and the cough leak point pressure. The maximal urethral closure pressure, the functional urethral length (FUL), and the length of the continence zone (LCZ) were measured using the urethral profile obtained from the UDS. The anatomical urethral length (AUL) was measured intraoperatively using a Foley catheter. We calculated the LCZ/FUL ratio to determine the anatomical continence length for this study. Results: We noted that 299 patients completed the study. The mean AUL was $26.25 \pm 3.59 \mathrm{~mm}$. The mean FUL and LCZ were $41.37 \pm 15.05 \mathrm{~mm}$ and $24.15 \pm 13.90 \mathrm{~mm}$, respectively. The mean LCZ/FUL was $0.57 \pm 0.19$. Using the Pearson correlation coefficient, we observed that the AUL showed a correlation with the FUL $(0.168, P=0.034)$, the $\operatorname{LCZ}(0.212, P=0.007)$, the LCZ/FUL ratio $(0.190, P=0.016)$, the Valsalva leak point pressure $(0.223, P=0.005)$, the cough leak point pressure $(0.215, P=0.006)$, and the maximal urethral closure pressure $(0.178, P=0.043)$.

Conclusion: Our results show that the AUL in women is associated with UDS parameters relating to SUI.

Keywords: stress urinary incontinence, urethral length, urodynamics, women

\section{Introduction}

Stress urinary incontinence (SUI) is defined as an involuntary loss of urine that occurs with a rise of intra-abdominal pressure. ${ }^{1}$ SUI affects the quality of life in women and their self-esteem, leading to physical and social restriction. ${ }^{2}$ The primary etiological factors associated with urethral dysfunction leading to SUI are urethral hypermobility and intrinsic sphincter deficiency. ${ }^{3}$ The lack of urethral support is an important pathomechanism that explains urethral hypermobility. ${ }^{3}$ Lack of urethral support allows the urethra to descend below the level of the pelvic floor, outside the region of favorable pressure transmission, and is considered the causative mechanism of SUI. Furthermore, the actual nature of the urethra, which is supported by several surrounding structures, may influence the development of SUI. We conclude that the length of the urethra in women is an important factor associated with the occurrence of SUI.

In men, several studies have evaluated the impact of urethral length prior to undergoing a radical prostatectomy and determined that continence slowly recovered in those with a shorter urethral length noted before surgery. ${ }^{4,5}$ However, to date, no studies have investigated the relationship between the length of the urethra in women and the occurrence of SUI. We performed this study to determine this relationship and 
to primarily evaluate the relationship between the anatomical urethral length (AUL) and urodynamic parameters.

\section{Patients and methods Patients}

Our study included 391 women who underwent a transobturator adjustable tape (TOA) sling implantation procedure (A.M.I TOA Sling, A.M.I GmbH, Feldkirch, Austria) for the management of SUI between April 2009 and March 2016. All patients were enrolled after obtaining written informed consent. This study was approved by the Institutional Review Board of Chonbuk National University Hospital. Exclusion criteria included patients presenting with a cerebrovascular accident, dementia, Alzheimer's disease, multiple sclerosis, Parkinson's disease, spinal cord injury, malformations resulting in gross neuropathy, detrusorsphincter dyssynergia, current urinary tract infection, and/or pelvic organ prolapse.

\section{Methods}

A medical history was obtained from each patient. All patients underwent physical examination and urodynamic studies (UDSs). UDS was performed with Duet sensic (Mediwatch, Rugby, UK) by one of the attendant nurses in the presence of a doctor. The methods and units of UDS assessed were in conformity with the standards/guidelines recommended by An International Urogynecological Association/International Continence Society joint report on the terminology for female pelvic floor dysfunction. ${ }^{6}$ UDS consisted of uroflowmetry followed by a filling and voiding cystometry, which were performed interactively with the patient. Uroflowmetry data included the maximal flow rate (Qmax), time to Qmax, and the voided volume, as well as the post-void residual urine volume (PVR). Filling cystometry data included the maximal cystometric capacity (MCC), the cough leak point pressure (CLPP), and the Valsalva leak point pressure (VLPP). The maximal urethral closure pressure (MUCP), the functional urethral length (FUL), and the length of the continence zone (LCZ) were measured using the urethral pressure profile obtained from the UDS. Furthermore, we calculated the LCZ/FUL ratio and measured the AUL using a Foley catheter just prior to the TOA sling procedure that was performed by a single surgeon under spinal/general anesthesia. The Foley catheter was gently inserted into the urethra, and the balloon was inflated using $3 \mathrm{cc}$ of normal saline. Next, the catheter was gently pulled to confirm that the balloon had been correctly positioned and was located at the bladder neck. Following confirmation that the balloon had been properly positioned, a mark was made on the catheter at the margin of the urethral meatus. The AUL was measured from the base of the balloon to this mark using a rigid ruler. Calculations were rounded off to the nearest $0.1 \mathrm{~cm}$.

Successful surgery was defined as the absence of any episodes of involuntary urine leakage during usual activities and a stress test that was negative 3 months postoperatively.

\section{Statistical analysis}

The correlation between UDS parameters and the AUL was assessed using the Pearson correlation coefficient. All statistical analyses were performed using the SPSS 18.0 software package (SPSS Inc., Chicago, IL, USA). A $P$-value of $<0.05$ was considered statistically significant.

\section{Results}

Of the 391 patients enrolled in the study, 92 withdrew from the study owing to non-availability of complete UDS data and because they met the exclusion criteria. Thus, we retrospectively studied 299 patients. The characteristics of the study population are described in Table 1. The mean patient age was $57.73 \pm 10.18$ years. The mean parity (number) and the body mass index $\left(\mathrm{kg} / \mathrm{m}^{2}\right)$ were $3.08 \pm 1.45$ and $25.50 \pm 3.32$, respectively. Diabetes mellitus and hypertension occurred in $12.3 \%$ and $24.8 \%$ of the patients, respectively. The overall cure rate was observed to be $90.63 \% 3$ months postoperatively. The mean AUL was $26.25 \pm 3.59 \mathrm{~mm}$ (Table 2). The mean FUL and LCZ were $41.37 \pm 15.05 \mathrm{~mm}$ and $24.15 \pm 13.90 \mathrm{~mm}$, respectively (Table 2). The mean VLPP, CLPP, and MUCP were $83.74 \pm 21.67 \mathrm{~mm}, 101.25 \pm 16.80 \mathrm{~mm}$, and $71.13 \pm 28.60$, respectively (Table 2 ). Using the Pearson correlation coefficient, we observed that the FUL $(0.168, P=0.034)$, the $\operatorname{LCZ}(0.212, P=0.007)$, and the LCZ/FUL $(0.190, P=0.016)$ showed a correlation with the AUL (Table 3). Moreover, the VLPP (0.223, $P=0.005)$, the CLPP $(0.215, P=0.006)$, and the $\operatorname{MUCP}(0.178, P=0.043)$ showed a correlation with the AUL (Table 3).

Table I Clinical characteristics of women with stress urinary incontinence

\begin{tabular}{lll}
\hline Variables & Values & \\
\hline Mean age (years) & 57.73 & (range: 34-87) \\
Body mass index $\left(\mathrm{kg} / \mathrm{m}^{2}\right)$ & 25.50 & $\begin{array}{l}\text { (range: 17-36) } \\
\text { Mean parity (n) }\end{array}$ \\
$\begin{array}{l}\text { Medical history } \\
\text { Diabetes mellitus (n) }\end{array}$ & 3.08 & \\
Hypertension $(\mathrm{n})$ & 37 & $(12.3 \%)$ \\
$\quad$ Cardiovascular accidents $(\mathrm{n})$ & 74 & $(24.8 \%)$ \\
\hline
\end{tabular}


Table 2 Anatomical urethral length and urodynamic parameters of study population

\begin{tabular}{ll}
\hline Variables & Mean \pm SD \\
\hline Anatomical urethral length $(\mathrm{mm})$ & $26.25 \pm 3.59$ \\
Functional urethral length $(\mathrm{mm})$ & $41.37 \pm 15.05$ \\
Length of continence zone $(\mathrm{mm})$ & $24.15 \pm 13.90$ \\
Length of continence zone/functional & $0.57 \pm 0.19$ \\
urethral length ratio & \\
Maximal cystometric capacity $(\mathrm{mL})$ & $405.93 \pm 101.75$ \\
Maximal flow rate $(\mathrm{mL} / \mathrm{s})$ & $23.47 \pm 9.99$ \\
Post-void residual urine volume $(\mathrm{mL})$ & $20.00 \pm 21.09$ \\
Valsalva leak point pressure $\left(\mathrm{cmH}_{2} \mathrm{O}\right)$ & $83.74 \pm 21.67$ \\
Cough leak point pressure $\left(\mathrm{cmH}_{2} \mathrm{O}\right)$ & $101.25 \pm 16.80$ \\
Maximal urethral closure pressure $\left(\mathrm{cmH}_{2} \mathrm{O}\right)$ & $71.13 \pm 28.60$ \\
\hline
\end{tabular}

\section{Discussion}

Recent studies have reported that the urethral length features as a significant factor associated with urinary continence after a radical prostatectomy. ${ }^{4,5}$ Interestingly, von Bodman et al have reported that the FUL in men was significantly associated with a faster recovery of continence at 6 and 12 months. ${ }^{4}$ While, the female urethra is a shorter structure without a complex structure compared to the male urethra. ${ }^{7}$ In women, the urethra is approximately $4.8-5.1 \mathrm{~cm}$ in length. ${ }^{7}$ The proximal two-thirds is lined by the transitional epithelium, whereas the distal one-third is lined by stratified squamous epithelium. ${ }^{7}$ The mean AUL of patients presenting with SUI was observed to be $26.25 \pm 3.59 \mathrm{~mm}$ in our study. This value was less than the mean urethral length observed in the general population. ${ }^{7}$ However, to date, very few studies globally have described an association between the urethral length in women and SUI. Based on the fact that the height varies among people, we calculated the LCZ/FUL ratio to determine an actual continence length for this study. This concept of

Table 3 Pearson correlation coefficients of anatomical urethral length with urodynamic parameters

\begin{tabular}{lll}
\hline Variables & $\begin{array}{l}\text { Pearson } \\
\text { correlation } \\
\text { coefficients }\end{array}$ & P-value \\
\hline Functional urethral length & 0.168 & 0.034 \\
Length of continence zone & 0.212 & 0.007 \\
Length of continence zone/ & 0.190 & 0.016 \\
functional urethral length ratio & & \\
Maximal cystometric capacity & 0.050 & 0.527 \\
Maximal flow rate & 0.041 & 0.609 \\
Post-void residual urine volume & -0.122 & 0.396 \\
Vasalva leak point pressure & 0.223 & 0.005 \\
Cough leak point pressure & 0.215 & 0.006 \\
Maximal urethral closure pressure & 0.178 & 0.043 \\
\hline
\end{tabular}

measuring the urethral length that we have suggested in our study is a novel one. The LCZ/FUL ratio is the actual continence length at which the urethral pressure must be considered a sum of a number of complex interactions between various parameters that are measured using UDS. The AUL is the actual urethral length that is measured using a ruler. In this study, the LCZ/FUL ratio determined by UDS showed a positive correlation with the AUL as would be expected.

VLPP is defined by the International Continence Society as an intravesical pressure that exceeds the continence mechanism, which results in leakage of urine in the absence of a detrusor contraction. ${ }^{1}$ VLPP measurement offers an objective means of assessing urethral function and incontinence, which is the intra-abdominal pressure at which urethral resistance is overcome and causes urine leakage. ${ }^{8}$ VLPP is a useful method to measure the degree of SUI. The CLPP is an alternative method to evaluate SUI, particularly when the measurement of VLPP is difficult/impossible if the Valsalva maneuver does not generate adequate pressure to enable assessment of the VLPP. ${ }^{8}$ The results of our study revealed that the AUL positively correlated with the VLPP and the CLPP.

MUCP refers to the difference between the maximum urethral pressure and the bladder pressure, which correlate to the junction of the striated and smooth muscle sphincters. Measurement of the MUCP is considered an objective criterion that represents the ability of the urethra to prevent urinary leakage. ${ }^{9}$ In women with SUI, the MUCP was 43\% lower than that observed in asymptomatic women. ${ }^{10}$ Moreover, recent studies have shown that a low MUCP was associated with a failure of surgery for SUI in women. ${ }^{11,12}$ The results of our study revealed that the AUL was observed to positively correlate with the MUCP.

Limitations of our study include: 1) the retrospective study design could have affected the primary acquisition of data; 2) our study was restricted to only those women who had been diagnosed with SUI. A greater number of studies that include a larger number of patients and multi-institution studies are warranted in future to validate the findings of this study and establish a cutoff point of the AUL, which could be useful in the clinical setting.

\section{Conclusion}

Our results showed that the AUL in women was associated with UDS parameters relating to SUI. The AUL remains a valuable adjunct in the evaluation of women presenting with SUI. Assessment of the AUL could give information that can be derived from UDS. 


\section{Acknowledgments}

This paper was supported by a Fund from the Biomedical Research Institute, Chonbuk National University Hospital.

\section{Disclosure}

The authors report no conflicts of interest in this work.

\section{References}

1. Haylen BT, de Ridder D, Freeman RM, et al. An International Urogynecological Association (IUGA)/International Continence Society (ICS) joint report on the terminology for female pelvic floor dysfunction. Neurourol Urodyn. 2010;29(1):4-20.

2. Lionis C, Vlachonikolis L, Bathianaki M, Daskalopoulos G, Anifantaki S, Cranidis A. Urinary incontinence, the hidden health problem of Cretan women: report from a primary care survey in Greece. Women Health. 2000;31(4):59-66.

3. Wilson PD, Herbison RM, Herbison GP. Obstetric practice and the prevalence of urinary incontinence three months after delivery. $\mathrm{Br} J$ Obstet Gynaecol. 1996;103(2):154-161.

4. von Bodman C, Matsushita K, Savage C, et al. Recovery of urinary function after radical prostatectomy: predictors of urinary function on preoperative prostate magnetic resonance imaging. J Urol. 2012; 187(3):945-950.
5. Song C, Doo CK, Hong JH, Choo MS, Kim CS, Ahn H. Relationship between the integrity of the pelvic floor muscles and early recovery of continence after radical prostatectomy. J Urol. 2007;178(1):208-211.

6. Haylen BT, de Ridder D, Freeman RM, et al. An International Urogynecological Association (IUGA)/International Continence Society (ICS) joint report on the terminology for female pelvic floor dysfunction. Int Urogynecol J. 2010;21(1):5-26.

7. Gordon D, Groutz A. Evaluation of female lower urinary tract symptoms: overview and update. Curr Opin Obstet Gynecol. 2001;13(5): 521-527.

8. McGuire EJ, Fitzpatrick CC, Wan J, et al. Clinical assessment of urethral sphincter function. J Urol. 1993;150(5 Pt 1):1452-1454.

9. Lose G, Brostrøm S. Low-pressure urethra in women: what does it mean and what can it be used for? Int Urogynecol J Pelvic Floor Dysfunct. 2002;13(4):215-217.

10. Delancey JO. Why do women have stress urinary incontinence? Neurourol Urodyn. 2010;29(Suppl 1):S13-S17.

11. Sun MJ, Sun R, Li YI. A comparative study of a single-incision sling and a transobturator sling: clinical efficacy and urodynamic changes. Int Urogynecol J. 2013;24(5):823-829.

12. Sun MJ, Sun R, Tseng SH. Is single incision midurethral sling effective in patients with low maximal urethral closure pressure? Taiwan $J$ Obstet Gynecol. 2016;55(1):20-25.
International Journal of Women's Health

\section{Publish your work in this journal}

The International Journal of Women's Health is an international, peerreviewed open-access journal publishing original research, reports, editorials, reviews and commentaries on all aspects of women's healthcare including gynecology, obstetrics, and breast cancer. The manuscript management system is completely online and includes

\section{Dovepress}

a very quick and fair peer-review system, which is all easy to use. Visit http://www.dovepress.com/testimonials.php to read real quotes from published authors. 